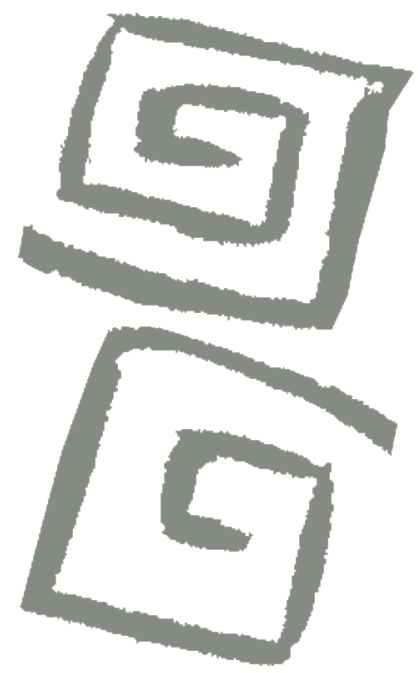

\title{
The relationship between violence and depression in migrant women through their experiences in care services
}

\author{
Relación entre violencia y depresión en mujeres \\ migrantes a través de las experiencias en los servicios \\ de atención
}

Nadia Irina Santillanes Allande ${ }^{1}$

${ }^{1} \mathrm{PhD}$ in Medical Anthropology. Carrying out post-doctoral studies, Instituto de Investigaciones Sociales, Universidad Nacional Autónoma de México, Mexico City, Mexico. $\square$ (iD)

\begin{abstract}
Based on ethnographic work with undocumented immigrant women who developed depressive episodes due to various forms of violence, this article recovers the women's experience of care in the clinic space of their host country. Through therapeutic itineraries of care, the article focuses on the case studies of two women of Mexican origin in New York City to describe, based on their experience, the communication and the encounter between the doctor and patient; the expectations of migrant women regarding mental health care services; and the explanatory models of depression of both the patients and the treating physicians. This analysis seeks to contribute to the knowledge regarding ways of treating the mental health problems of undocumented women in contexts of violence.
\end{abstract}

KEY WORDS Mental Health; Women 's Health; Migrants; Depression; Emergency Medical Services; United States of America.

RESUMEN A partir del trabajo etnográfico con mujeres inmigrantes indocumentadas que desarrollaron episodios depresivos a causa de diversas formas de violencia, se recupera su experiencia sobre la atención que recibieron en el espacio clínico del país de acogida. A través de itinerarios terapéuticos de atención, el trabajo se centra en los estudios de caso de dos mujeres de origen mexicano en la ciudad de Nueva York, para describir, con base en su experiencia, la comunicación y el encuentro entre médico y paciente; las expectativas de las migrantes en relación con los servicios de atención en salud mental; y los modelos explicativos sobre la depresión por parte de los pacientes y los médicos tratantes. Con lo anterior, buscamos contribuir al conocimiento sobre las formas de atención de los problemas de salud mental de mujeres indocumentadas en contextos de violencia.

PALABRAS CLAVES Salud Mental; Salud de la Mujer; Migrantes; Depresión; Servicios Médicos de Urgencia; Estados Unidos de América. 


\section{INTRODUCTION}

Access to medical care is a basic human right that should be provided without differentiation, recognizing every person as equal. Nevertheless, this does not occur when distinctions are made in the provision of services among citizens, residents, and immigrants in a large part of receiving countries. ${ }^{(1)}$ Even when international conventions and agreements have been signed to recognize the right of all people to physical and mental health, in practice, these health institutions provide differentiated access. Such is the case in the United States; even though the country has signed on to the International Covenant on Economic, Social, and Cultural Rights, as well as the International Convention on the Protection of the Rights of all Migrant Workers and Members of their Families, ${ }^{(2)}$ it continues to provide limited assistance to those with irregular immigration status.

For those immigrants who are unable to regularize their migratory status in host countries, this lack of clarity regarding the enjoyment of healthcare services extends to mental health care. Adding to this is their economic disadvantage and vulnerability derived from the conditions that led to their displacement to another country, above all when this departure is not due to economic motives, but rather because of violence or environmental emergencies that render these new migratory waves even more vulnerable. ${ }^{(3)}$

Moreover, as studies on the impact of migration on mental health have shown, if the motive of relocation from one country to another is forced, negative events during the transit or an unfavorable process of adjustment due to discrimination or exclusion in the destination country can present themselves, making the process even more stressful. ${ }^{(4)}$ This situation must also take into consideration the tightening of border control that has generated networks of human trafficking that put immigrants at greater risk, exacerbating their experience during transit. ${ }^{(5)}$ Host countries are generating a series of immigration policies that contribute to the restriction of certain fundamental rights, as is the case of the petition for asylum in the United States. ${ }^{(6)}$ With the objective of contributing to the complex relationship that exists between mental health and migration, this study seeks to include an analysis of mental health care in the clinical space of the host country. In order to do so, it is necessary to describe the paths taken in the search of care and the experiences in the few spaces to which immigrants manage to gain access to receive mental health care. While public health literature has detailed the personal, geographic, economic, and personal barriers, as well as the barriers presented by the healthcare system itself, in the immigrants' search for mental health, it is also important to consider the following based on the immigrants' experiences: 1) the encounter in the clinic between physician and patient; 2 ) the immigrants' expectations about healthcare services for mental health; 3) both the patients' and treating physicians' models of the health/disease/care process of depression.

A good reference given its sheer size is the case of Mexican migration to the United States, with almost 12 million immigrants of Mexican origin. ${ }^{(7)}$ Due to the proximity between the two countries, the Mexico/US border is one of the most highly transited, with the largest number of crossings of people both with and without documentation. ${ }^{(8)}$

To discuss the experience of mental health care, this research will make use of information generated in an ethnographic study with six migrant women who live in the United States and developed problems of depression in the country. The information and the data presented are the result of ethnographic research with undocumented migrants of Mexican origin in New York City that was carried out in two extended stays, for a total period of ten years.

The general objective of this research is to understand the conditions of the health/ disease/care process of depression in a group of women that had to migrate from Mexico to the United States without documentation. While these women have lived and worked for more than 20 years in the country, they 
continue to have an irregular migratory status, which subjects them to a number of situations of vulnerability. As the research delved into their stories, diverse forms of violence they had experienced throughout their lives could be identified. This psychological and physical violence in most cases was perpetuated by family members, employers or their intimate partner.

A central aspect of this work relates to the search for mental health resources that help migrant women in moments of great severity and suffering. In this way, encounters with allopathic physicians and community organizations were explored as part of the paths that women follow in pursue of attention. At the same time experiences of care and the interpretations of the condition by the patient and physicians were followed up on and documented. The article also presents the case studies of two migrant women who narrate their experience receiving biomedical care after suffering severe crises stemming from violent events in their homes.

It is of utmost importance to discuss these findings within the framework of the difficulties that many migrants in the world face, not only in accessing mental health services, but in the communication between physician and patient in a context in which stories of difficult life conditions and violence are common. As such, the objective of this research is to contribute to and rethink, based on the subjectivity and explanatory models of patients in contexts of migration, the forms of care in the biomedical health sector in order to improve the experience of mental health care for immigrants and thus contribute to the development of best practices and culturally sensitive knowledge.

\section{METHODOLOGY}

To fulfill the objective of this research - which is to understand the experiences of care, comprehension and interpretation from the point of view of migrants who suffer and cope with problems of depression - the methodology, techniques, and tools of anthropology have been of great use. For example, to explore the meaning and interpretation of mental health illness, an emic approach, based on the perspective of the subject, was used. For this purpose, explanatory models were recovered from the women's stories and experience with depression and malaise, ${ }^{(9)}$ including the causality or what they attributed to their depressive episodes, the symptoms or the indicators that made them believe that they suffered from depression, the search for care, and the interpretation of the medical diagnosis, as well as the search for other treatments and therapies to improve their situation. ${ }^{(10)}$

Depression was approached as a health/ disease/care process; while this concept includes a biological dimension, the social, economic, cultural and power dimensions observed in the experiences and the meanings of the social subjects were central to this research. ${ }^{(11)}$ From this framework, the objective was to understand what brought about the suffering and affliction from the point of view of the social actors and the intersections with the life conditions or contexts that gave rise to these illnesses.

The theoretical framework is that of interpretive anthropology, because from this perspective it is fundamental to consider the way the actor perceives, experiences and thinks about the health/disease/care process. In this vein, the notion of illness was very useful, as the description of the condition is provided by the subject. This term not only expresses subjectivity, but also the representations and the sociocultural practices regarding the experience. ${ }^{(11)}$

The ethnographic data was constructed from interviews and observations in spaces where women carried out their daily lives. Given that preliminary information indicated that part of the women's anxiety and suffering originated from the domestic space or from disputes among the members of their community of origin, women were observed in the clinic and in their homes. This provided us with a type of comprehension different from the medical representation about mental health since the narratives carry the 
experience of depression beyond the clinical space and discourse. ${ }^{(12)}$

The following criteria were used to select women to form part of a sample that sought to represent first-generation women who due to economic difficulties were forced to migrate to New York City and have remained there under an irregular legal status:

1. That they be undocumented residents in the United States, in order to understand what the lack of access to health insurance means and to register the shortage of available mental health services for this population.

2. That they be of Mixteca origin from the state of Puebla, given that in this region there is an ample migratory circuit that fulfills the labor force demand in the service industry of New York City. ${ }^{(13)}$ This sector of the population also represents the rural-urban migration that arose from various agricultural reforms at the beginning of the 1990s, which fueled mass migration to the United States.

3. That they have a diagnosis of depression by a biomedical institution, since this research has a specific interest in understanding the experience of migrants in allopathic care services in the United States.

With these criteria in mind, fifteen women were interviewed; this number was then narrowed to six participants who were chosen not only because they fulfilled the selection criteria, but also because the objective of the research required building rapport or sufficient trust to interact and broach topics related to violence and depression. On the other hand, it is widely known that people in interviews usually omit information, and they may even have representations regarding some aspects of reality that do not correspond to their everyday practices. Because of this, and in order to avoid these biases, anthropologists seek to each day carry out observations that are both systematic and relational with other actors that form part of the social group. ${ }^{(11)}$
Two instruments were developed to obtain information. The first was the migration trajectory, in which the interviewees described their life from their place of origin up until their destination. The objective of this instrument was to understand their life experience and in what material conditions people are forced to migrate and live in the United States. This trajectory also explored their life before coming to the United States, their family relations, their economic situation, the conditions under which they traveled and arrived to New York City, followed by aspects related to their work, life, health and sociability.

The second instrument, and the one that generated that majority of the information that will be discussed below, was the therapeutic itinerary of the health/disease/care process. Also called health-seeking behavior, ${ }^{(10)}$ this concept allows the researcher to identify a complex pattern of treatment that can be structured in a series of phases, from the identification of some pathological process (defined in biological, psychological or even cultural terms), up until the selection of treatment and its application based on available resources. ${ }^{(14)}$

The abovementioned instruments allowed us not only to explore experiences regarding the diverse resources of care, but also the prior and posterior interpretation of what depression is. The experiences of the participants with allopathic health care services were complemented with interviews conducted with various physicians that work directly in mental health care services with undocumented populations. The information provided by the healthcare personnel clearly shows the process that an immigrant must follow in order to see a specialist, especially because the information provided by the women focused more on their impressions of the consultation than on details about the bureaucratic procedures that they had to follow.

The normative guidelines and legislation in the country where the field work was carried out did not require the research project to be evaluated by an ethics committee. Nevertheless, and because the results of this 
research are part of a $\mathrm{PhD}$ thesis presented to the Center for Research and Advanced Studies in Social Anthropology (CIESAS-CDMX) [Centro de Investigaciones y Estudios Superiores en Antropología Social], the institution's ethical guidelines and recommendations were followed. One of these guidelines was obtaining informed consent from every participant, for which we provided information about the research in an easily comprehensible manner, giving sufficient detail so that participants had the opportunity to either refuse or express interest in participation, free of coercion, intimidation, influence or undue incentives. Additionally, the personal data and identity of participants have been protected through the use of pseudonyms, which is particularly important given this population has an irregular legal status in the United States.

\section{RESULTS}

The women's migratory condition determined the eligibility and quality of healthcare services. In order to access medical care, hospital attention, home-based care and/or medicine, one must have private health insurance issued by an employer. In this sense, the right to possess private health insurance is a right only available to those who are formally inserted into the labor market, which ultimately requires a work permit or status as a citizen or permanent resident of the United States. Women that do not have legal status have only three options for healthcare: 1 ) the emergency room, 2) basic healthcare through community health centers principally financed by foundations, and 3) other services offered by social security programs, such as Medicaid.

The majority of the undocumented population does not have access to these social security programs because in order to receive these benefits, the person must be a citizen or resident of the United States. ${ }^{(7)}$ On the other hand, it is widely known that without health insurance, the majority of people cannot afford the high, out-of-pocket expense of private healthcare services. ${ }^{(15)}$ Visiting a clinic or an emergency room can range between USD $\$ 15$ and $\$ 100$. This situation creates a large degree of exclusion from the US healthcare system for the Mexican immigrant population, who constitute $3.8 \%$ of the total resident population in the country and represent approximately $13 \%$ of the entire uninsured population. As such, in 2012, about $53 \%$ of US residents of Mexican origin lacked any type of insured medical coverage. ${ }^{(7)}$

Regarding access to mental health care, the situation and the data presented are very similar. There is even information about the low use of these services by the Latino population, which has generated a debate regarding whether supernatural belief systems combined with traditional healers has functioned as an alternative. ${ }^{(16)}$ The controversy over whether this situation is due to the use of other resources, a lower prevalence of psychiatric disorders or simply because of the organizational barriers to these services still continues. ${ }^{(17)}$

In the presentation of the following cases, it can be observed that belief systems do not play a part in hindering the search for mental health care services. What is worth noting, however, is that the access to a therapist is not simple for populations with little economic capital. The consultation with a therapist or a psychiatrist can oscillate between USD $\$ 100$ and $\$ 300$, which is nearly impossible to cover without some type of medical insurance. Essentially, for a population with irregular migratory status, the emergency room remains the only option for mental health care.

Even though the first consultation in the emergency is free, it is difficult to provide continuity to the treatment since physicians require patients to have health insurance to establish a plan for care. The care provided in the emergency room also plays an important role in referrals for the population that suffers some form of domestic violence to the Violence Intervention Program (VIP) in New York. In interviews with healthcare providers, it was indicated that it is in the 
emergency room where most problems of family violence are detected. In this sense, in addition to providing an initial diagnosis, general physicians are also trained to detect problems of violence and redirect the victim to social workers who, in turn, will accompany patients before the specialized agencies that provide protection against diverse forms of violence.

The emergency room is an important part of a mechanism of attention, referral and reporting of domestic violence since another of its functions is to report problems of home violence to the State, especially if this violence is towards a minor or witnessed by one. Any case of violence or impropriety against a child must be reported to the Administration for Children's Services (ACS) so that the case may be brought to court.

Adding to the difficulties in accessing public health services, the public health literature has identified a series of personal, geographic and economic barriers, as well as barriers posed the health system itself, in the search for mental healthcare. Martínez Pincay y Guarnaccia ${ }^{(18)}$ identified and organized the barriers faced by the Latino population that lives in the US into three dimensions: 1) barriers in the service system; 2) barriers at the community level and in social networks; 3) personal or individual barriers.

All of these factors are interconnected and present themselves in various circumstances in the lives of Latino immigrants. ${ }^{(19,20)}$ An example of these barriers can be observed in the itineraries of the interviewed women. While the most obvious and documented barriers are related to their legal status, in the following pages, we will describe others that have to do with bad experiences in emergency rooms. As was documented in the majority of the interviews, emergency rooms continue to be the space of care for problems of depression among the population with this profile.

The following two case studies that formed part of the research allow us to comprehend the women's experiences of care in the emergency room. As we highlighted in the methodology, six in-depth case studies were developed; however, for the objectives of this paper, we have chosen the cases of Frida and Regina, for in these two cases, we can clearly see the type of care they received in the emergency room in their moments of crisis. Likewise, and even more importantly, we can see the options that they sought out to resolve their mental health problems when faced with a lack of efficiency in the health care provided, especially in the case of Regina.

\section{Case studies: Frida and Regina}

Frida and Regina are part of the women that made up the migratory flow from Puebla to New York that began more than three decades ago. At the beginning of the 1980s, with the opening of a series of jobs in the service industry like domestic and manufacturing work in New York City, a number of women joined this labor market. ${ }^{(13)}$ Many of them were invited or recruited by family members that had previously worked there, sent by their parents to contribute to the household economy. However, having entered the United States after the last amnesty, these women were not able to regularize their immigration status and continue to reside in the US without documentation.

\section{Frida}

We will first present the case of Frida, who indicated that she had experienced three episodes of depression over the course of her life. All three episodes were closely linked to problems found with the three intimate partners with whom she tried to form a family in the United States. Below, we will summarize the second episode - one of the most severe - related to diverse forms of violence that she experienced with her last partner.

The relationship lasted eight years and gave rise to Frida's second child. During the last three years, the relationship was full of problems related to infidelity and the restrictions that her partner imposed on her to carry out activities outside of the house. Because of this, even though there were attempts to 
change the dynamic through the support of groups like Neurotics Anonymous, their disputes became increasingly more frequent and violent.

According to Frida, the episodes of physical violence included humiliation by her partner, who justified his aggressions and attributed them to his problems of neurosis and the violence that he suffered as a child. Due to this violence, Frida began to become depressed and suffer anxiety attacks. Here are Frida's words describing one of the most severe moments that included physical suffering:

After a big problem with Martin, I started to experience tachycardia and I felt numbness in my mouth, and, well, I think more than anything, it was the tachycardia [...]. In fact, I ended up in the emergency room. My chest hurt and I began to feel like my left arm was getting numb, my middle finger, and these veins [on my arm] began to swell, and it hurt, it hurt. (Frida, New York, August 2012)

With these symptoms, Frida decided to go to the emergency room. When the physicians did not detect a health problem, they told her that she needed to calm herself because she seemed very agitated. Additionally, they asked her to speak to a social worker and file a report, because they suspected that she was suffering physical violence from her intimate partner.

Frida did not file a report with the social worker out of fear that her partner would be deported or that the State would try to take custody of her children. However, the problems with her partner continued up until a following episode where she once again experienced a series of pains in her arms and chest. She went back to the emergency room at the Metropolitan Hospital. When the medical staff asked her how she felt, she began to cry. This time the physicians asked her if she wanted to be hospitalized in the psychiatric area until she could calm down, which she accepted:
The doctor sensed that I was going through something serious, and I don't know how he decided that I needed to go to the psychiatric unit without even evaluating me, because there was no social worker, or maybe there was a social worker, but they aren't psychologists and don't have the sensitivity to handle each person's problems or needs. It's like the healthcare staff are made of stone in the way they treat you. It's like they're there because they need to get paid, but not out of love for their profession, it's only a job and they need a salary, and at the time it is the only thing they could find, right? We got to the psychiatric area [...] I mainly saw people that were on drugs or drunk and didn't remember where they lived. (Frida, New York, August 2012)

Frida decided to stay because at that moment, she wanted to be away from her partner, and she signed her consent. Given that there was no space exclusively for women in the common areas, she began to become fearful for her safety:

The worst part was going to sleep at night. I thought that they were going to send me to a normal room. The beds were like rocks, the mattress very thin like this, no blankets, and just a sheet so you were cold all night. So, apart from the depression or anxiety that you have, there is the fear that one of these people is going to choke you because you can't even lock the bathroom door. When I agreed to stay there, it was to escape my problems for a little while, but then I had another fear: one of being inside there. And at the same time I thought, "they aren't going to diagnose me right," "they're going to give me drugs," "I'm not going to get out of here alive." (Frida, New York, August 2012)

In the psychiatric unit, Frida wanted to find psychological support or someone that would listen to the problems that she was experiencing with her partner, however, this is 
how she describes her experience during the psychological evaluation:

\begin{abstract}
It seemed like [the questions] were whatever occurred to them, but at the same time, it was really important to me that I tell them everything so that they would see that I was sane. Yes, I did have an emotional imbalance, but I wasn't crazy. So I tried to be very clear in English and tell them where I was born, my frustrations, what my mom once gave me when I was young, my sadness about living in the US without documentation, the death of my father; I told them about a little of everything, everything that pained me, in my [basic] English. I say that I don't speak English, but at that moment, I could translate what they were saying and tell them all that. That made me think that I can get by [with my English]. And they decided that if I wanted to go home with the father of my child, then I could. They let me leave with him. (Frida, New York, August 2012)
\end{abstract}

Because Frida did not report a situation of violence with her partner this time, she felt that they did not provide her with the care that she needed and came to the following conclusion:

\begin{abstract}
More than anything, when the doctors affirm or confirm that you are in a serious situation, it's because you want to jump off a train, [...] to commit suicide. So that is when the situation is serious [and they provide medical care], but if you feel like crying, well then it is not so serious. It is serious when you feel like you are going to kill somebody, kill yourself or jump off a train... (Frida, New York, August 2012)
\end{abstract}

In this section, like in other interviews, Frida affirmed that the care in the biomedical space did not meet her expectations, since she was looking for psychological attention and instead only found a space to be contained during her crisis. In the emergency room and in the psychiatric unit, she sought a space where she could be heard and was met only by the social workers' interest to detect problems of violence in her home.

Frida attributes her malaise and anxiety ${ }^{(11)}$ to the family violence that she has experienced over her life, and above all the violence with her partners. On the other hand, this is the meaning of depression for her: for Frida, depression is not the same as sadness. For her, the three episodes described are different from sadness because, for example, for extended periods of time, she could not get out of bed or carry out everyday activities. Additionally, she suffered physical problems like tachycardia and chest pains, which according to her, are signs of depression.

\section{Regina}

Regina's is another case in which violence was related to episodes of depression. She is also of Mixtec origin from the Mexican state of Puebla and during her childhood, as the oldest, she was responsible for taking care of her siblings and had to clean houses for other people in order to contribute to the family economy. When she turned 15, her parents sent her to New York to work with her uncles in a factory. Going was an act of obedience and she says that she felt devalued for having been sent in that way to another country at such a young age.

After living in New York for five years, she met the father of her two daughters. Shortly after going to live with him, the problems began. One of the worst problems had to do with the fact that he wouldn't let her work outside of the house, saying that she would be neglecting her daughters. Another problem, and maybe the most important of all, was her partner's drinking and the physical and psychological violence that ensued because of this. Regina tolerated the aggressions because it is what she had seen in her parents' house and viewed it as normal.

Here we describe the most severe episode, when her partner shot her while inebriated. On this occasion, he had been drinking and during an argument, he shot at her. The bullet passed very close to her head 
and caused an injury in her ear. The police arrived after the neighbors filed a report and subsequently found the firearm. Regina decided not to press charges because her underage daughter saw the conflict, and as was previously mentioned, if authorities found out that a child has witnessed a violent act, the child would be placed under the state's custody. To avoid this and close the investigation, Regina stated that the firearm had gone off by accident; the police took Juan in on the charge of carrying a firearm without a permit. After the incident, she describes what she began to experience:

My face started to become paralyzed and my hand and leg went numb. I couldn't walk but I made it to the emergency room of the Metropolitan Hospital. I was unwell and my face was paralyzed. When I got to the hospital, they couldn't believe that I was walking. My nervous system was so affected that I couldn't handle [the treatment], so it had to be with medication. They also told me that I needed to go see a psychiatrist - not a psychologist, a psychiatrist - to be treated for my stress, since it was already so advanced. (Regina, New York, March 2012)

In addition to the physical problems, Regina also confided that she had a series of thoughts related to death and suicide:

I refused to accept the medication, because even though I feel this stress and depression, it must be so much easier to kill yourself, because maybe my place isn't here. When you start to think about those things, you aren't ok. I have thought about all of that, but what if I take poison and it doesn't work? And it only causes brain damage and everything is worse? And then I say, if I grab a knife, I won't have the patience to be there. I've also thought, what if I throw myself in front of the train, and if it just injures my legs? (Regina, New York, May 2012)
Regina refused to continue the treatment that the psychiatrist prescribed because it reminded her of her cousin who took medication for depression and it only made her condition worse. Out of fear of becoming dependent on pharmaceuticals, she preferred to solve the problems that she was experiencing on her own, until she found another space that she described as one of healing.

This space of healing was a pre-Hispanic Mexican Mexica Tiahui dance group that celebrates the knowledge of the Mexica philosophy. As part of their rituals, they dance and interpret songs accompanied by the rhythm of the huéhuetl instrument used in dances. ${ }^{(21)}$ According to Regina, she immersed herself in this activity, because in this space, she began to find meaning in her life. She felt a series of benefits, such as the possibility of involving herself more in public life, studying, and reading things to know about her origins. Additionally, according to Regina, the group accepted her like family:

The dance group was definitely my salvation - it was the only path that I found. It was how I could rebel against the father of my daughters and where I found strength to overcome my depression. My separation with Juan was also a result of the group, thanks to the group. When I joined the group, it's like they took the blindfold off. Why? I don't know. Because there, they don't teach you violence, they teach the exact opposite. The first piece of advice that the group gives you is that you be a good wife, a good mother or a good daughter because you need to give the example. It's what our grandparents did before, they were humble and respectful people. So I could release myself from Juan, but I think that I was able to release $50 \%$ of all that negative energy thanks to dancing. I don't know, maybe it's thanks to the exercise, maybe it's the essence or the strength of our grandparents or the work that I am doing through smudging [sahumación]. (Regina, New York, June 2012) 
On the other hand, Regina could also share with other group members who had also traversed difficult times in their lives. In this vein, the dance group became a space of socialization where she could participate and assume certain leadership. It is also important to note that the rituals in which dancers participate are not only limited to the performance as an expression of Aztec dance. They also participate in rituals such as velaciones [vigils] and temazcales [bath houses] that share practices in relation to the body, such as the sensory contact with the aroma of the plants that are burned in the smoker and the sound of the musical instruments (drums, whistles, diverse shells and mandolins). ${ }^{(22)}$ All of these practices, as Regina mentions, are part of their healing practices.

Finally, it is worth noting how interesting it has been to observe Regina's itinerary, and the way in which she has repositioned herself in the world since she began participating in the pre-Hispanic dance group. According to Regina, this has allowed her to release herself from her parents and feel better with herself. Finding this group has been significantly positive in dealing with her depression, since it has allowed her, among many things, to have a purpose and a renewed meaning in life.

\section{DISCUSSION AND CONCLUSIONS}

In mental health studies, medical anthropology has shown the importance of recovering explanatory models about the episode of illness and its treatment from the perspective of all those involved. ${ }^{(10)}$ This includes the notion of both the physician and the patient, with the objective of improving the communication in and understanding of the encounter between both parties. However, as we can observe in the case studies mentioned above, in the case of depression, the biomedical notion and the experience of each person differ. Although some affective symptoms of the biomedical definition (Diagnostic and Statistical Manual of Mental Disorders) of depression were identified by migrant women, there are also other interpretations that do not perceive depression as a disease. Frida, for example, defines depression as an emotional imbalance generated by intimate partner violence. In Regina's case, the apathy, dispassion and anxiety that she experienced were part of that depression that has accompanied her, along with family violence, over the course of her life. Even though violence is present throughout the lives of these women, there are moments when it is exacerbated. It is in these episodes in which the alteration leads them to experience physical problems such an accelerated heart rate, which subsequently leads them to personally seek out help in a clinical space.

Due to the symptomatology, and in this search for help outside the domestic and community space, the emergency room seems like the best place to turn to in these moments of crisis. Additionally, it is the only space that does not require documents or health insurance in order to receive care. However, the emergency room is not a space that specializes in mental health.

As the interviews with healthcare personnel confirmed, physicians in the emergency room experience a high demand to provide care to these types of cases. In addition to performing general, routine revisions, they are trained to inquire about the motives that led to the altered state of health of the patient. At the same time, and as part of the institutional framework for the detection of domestic violence, they have prior training in the detection of family violence cases and their referral to specialized organizations. As such, after on a consultation that lasts no more than 20 minutes, the physician must emit a patient diagnosis.

According to the women interviewed, a number of problems and a lack of comprehension on both parts are present in the diagnosis, communication, and referral process. For example, in the diagnosis and the prescription of medication for depression there are large discrepancies. The women interviewed understood that their mental health state stemmed from the physical and psychological violence suffered at the hands of their partners, the lack of family support 
to confront these circumstances, and the lack of community support that leads to isolation, thus considering that medication or a diagnostic label was not the solution to their conditions.

What patients expect from the clinical space is to unburden themselves of their problems, be listened to, and be comprehended without feeling judged. They also feel like there is always the danger of being reported to social workers and a potential State intervention. For example, Regina explained that Mexican people that live in the US - especially if they are undocumented - prefer not to tell the psychiatrist or psychologist anything for fear of having a social worker sent to their house who could then report them to State agencies for violence witnessed by minors. This leads to the separation of families and other problems, as one patient states:

If a psychologist asks you a question,
sometimes you can't hold back, so I
tried to control myself and not reveal
too much information. If they see some
type of violence, they will immediately
send a social worker that will get you to
talk, just like you are getting me to talk.
(Regina, New York, May 2012)

Regarding their experience with care, migrant women explained that they wished healthcare providers were more accessible and showed greater sensitivity in order to build trust. However, according to their stories, care seems to be based on a system that, by inertia, functions to treat migrant women in situations of violence, with radical options like reporting their partners, which for them represents grave consequences both in terms of family and community.

It is important to remember that in the United States, a report of domestic violence results in the deportation of the perpetrator, and if the event has been witnessed by children, the State can take custody of the children, thus separating them from their family. Therefore women often prefer to hide situations of violence due to economic interdependence with their partners or the fact that if their partners are deported from the United States, their children will be left without a father. Also, according to the women interviewed, the community will exercise certain social sanctions if a woman takes her case to these final consequences.

On the other hand, the interviewed women mentioned not taking the medicine prescribed because they did not consider themselves "sick." A number of them continued to look for help through their social networks. Such is the case of Regina, who, thanks to these networks, found a dance group that was therapeutic. By exploring more about what made the dance group curative and its relation to her depression, we gain insight into other issues that are important to these women and their illness, such as unburdening themselves and being listened to. In this space, Regina found purpose in her life after always living in obedience to her parents or her partner. The encounter with other people that experienced stories similar to her own helped her to feel less isolated, while dance served as a therapeutic release.

In conclusion, it is important to draw attention to the urgency of continuing to reflect on the relationship between various forms of structural violence and mental illness, as clinics continue to act as temporary spaces of support, according to the stories presented in this paper. The results of this research also highlight the importance of entering into conversation with other studies that are concerned with the relationship between biomedicine and the mental health of women. As Carme Valls-Llobet et al. ${ }^{(23)}$ warn, the health of women has been interposed by patriarchal influences in the development of health sciences, which has converted women more into an object of medicalization than into their own agents of change. These studies also show the importance of understanding mental health issues from the point of view of those who experience them, and not from the viewpoint of physicians considered to be specialists in problems that affect the mental health of women. ${ }^{(11)}$

For practical purposes, we can see the application of this line of research in the 
proposal made by Sara Velasco ${ }^{(24)}$ regarding primary health care services in the detection of violence against women in Spain. In this country, medical services are the first spaces of detection and are described as operating under a police-like model of care. As such, attempts have been made to integrate violence prevention activities in the clinic, such as changes in the training of and curriculum development for healthcare professionals in primary care. We could also add to this strategy the need for a sensitive follow-up, appropriate for the needs of women, that takes into consideration both experiential and subjective factors, mediated by the particular conditions of the women's lives.

When we reflect on the experience of women who search for healthcare to address their mental health issues, which are linked to family or intimate partner violence, we can also understand why in Mexico the percentage of women who seek formal support from institutions that provide services and support to eradicate violence is very low. Only $8.2 \%$ of women involved in intimate partner violence have sought help from women's institutions that offer consultation, social work services and/or legal support. ${ }^{(25)}$

This data, in addition to what has been presented throughout this study, reveals that while emergency room care in the United States fulfills the mandate of early detection, it is perceived as a hostile place for the follow-up of problems of violence, whether due to the fear of deportation or that of state intervention. Thus, these spaces are seen as punitive institutions, rather than ones of accompaniment.

\section{ACKNOWLEDGEMENTS}

I would like to thank the Postdoctoral Scholarships Program of the Universidad Nacional Autónoma de México (UNAM) for the support provided as scholarship recipient of the Institute of Social Research. I would also like to acknowledge the economic support for the development of the research that forms part of the project for Basic Science 2009 (SEP-CONACYT) entitled, "Construction and effects of fear in undocumented migration: a comparative study on borders, vulnerability and subjectivities," reference number CB-2009-01-127972. Lastly, I would like to express my immense gratitude for the financial support provided in 2012 by the Health Initiative of the Americas, School of Public Health,
Berkeley, California, as part of the Research Program on Migration and Health. Furthermore, there was no conflict of interests between the support and sources of financing provided by these institutions.

\section{REFERENCES}

1. Dwyer J. Illegal immigrants, health care, and social responsibility. The Hastings Center Report. 2004;34(1):34-41.

2. Organización Mundial de la Salud. Migración internacional, salud y derechos humanos [Internet]. 2003 [cited 10 Dec 2019]. Available from: https://tinyurl.com/ y27xakz8. 
3. United Nations High Commissioner for Refugees. Global Trends: Refugees, Asylum-seekers, Returnees, Internally Displaced and Stateless Persons [Internet]. 2010 [cited 10 May 2019]. Available from: https://tinyurl. com/3jee $5 \mathrm{mj}$ r.

4. Bhugra D. Migration and mental health. Acta Psychiatrica Scandinavica. 2004;109(4):243-258. doi: 10.1046/j.0001690x.2003.00246.x.

5. Álvarez S. Transitando en la clandestinidad: análisis de la migración indocumentada en tránsito por la frontera sur mexicana. Andina Migrante. 2009;(4):2-10.

6. Carrasco G. La política migratoria de Donald Trump. Alegatos. 2017;(95):171-194.

7. Secretaría de Gobernación, Consejo Nacional de Población. Migración y salud: Inmigrantes mexicanos en Estados Unidos [Internet]. 2013 [cited 10 Dec 2019]. Available from: https://tinyurl.com/hy254a6p.

8. Durand J, Douglas M. Clandestinos: Migración México-Estados Unidos en los albores del siglo XXI. México: Miguel Ángel Porrúa; 2003.

9. Burin M, Moncarz E, Velázquez S. El malestar de las mujeres: La tranquilidad recetada. Buenos Aires: Paidós; 2000.

10. Kleinman A. Patients and healers in the context of culture. An exploration of the borderland between anthropology, medicine and psychiatry. Berkeley: University of California Press; 1980.

11. Menéndez EL. La parte negada de la cultura: Relativismo, diferencias y racismo. Buenos Aires: Prohistoria Ediciones; 2010.

12. Dossa P. Politics and poetics of migration: Narratives of Iranian Women from the diaspora. Toronto: Canadian Scholars; 2004

13. Rivera-Batiz F. The state of Newyorktitlán: a socioeconomic profile of Mexican New Yorkers. New York: Columbia University; 2003.

14. Osorio Carranza RM. Entender y Atender la enfermedad: Los saberes maternos frente a los padecimientos infantiles. México: CIESAS, INI, INAH; 2001.
15. Quinhoes TAT, Fleury S. La reforma del sistema de salud de los Estados Unidos de América en los años 90. Salud Colectiva; 2006;(2):129-153. doi: 10.18294/ sc. 2005.41

16. Jaco EG. The social epidemiology of mental disorders: A psychiatric survey of Texas. New York: Sage Found; 1960

17. Vega W, Rumbaut R. Ethnic minorities and mental health. Annual Review of Sociology. 1991;17:351-383. doi: 10.1146/annurev.so.17.080191.002031.

18. Martínez Pincay IE, Guarnicca PJ. "It's like going through an earthquake": anthropological perspectives on depression among Latino immigrants. Journal of Immigrant and Minority Health. 2007; 9(1):17-28. doi: 10.1007/s10903-006-9011-0.

19. Cabassa L, Zayas L, Hansen M. Latino adults' access to mental health care: A review of epidemiological studies. Administration and Policy in Mental Health. 2006;33(3):316-330. doi: 10.1007/s10488-006-0040-8.

20. Rastogi M, Massey-Hastings N, Wieling E. Barriers to seeking mental health services in the Latino/a community: A qualitative analysis. Journal of Systemic Therapies. 2012;31(4):1-17. doi: 10.1521/jsyt.2012.31.4.1.

21. Olmos M. Las creencias indígenas y neo-indias en la frontera MEX/USA. Trace. 2008;54:45-60.

22. Olivas O. Danzar la frontera: Procesos socioculturales en la tradición de danza azteca en las Californias. México: Colegio de la Frontera Norte; 2018.

23. Valls-Llobet C. Mujeres, salud y poder. Valencia: Ediciones Cátedra; 2009.

24. Velasco S, López Doriga B, Tourné García M, Barceló Barceló I, Luna Rodríguez C. Evaluación de una intervención biopsicosocial para el malestar de las mujeres en atención primaria. Feminismos. 2007;10:111-131.

25. Leone J, Lape M, Xu Y. Women's decisions to not seek formal help for partner violence: A comparison of intimate terrorism and situational couple violence. Journal of Interpersonal Violence. 2014;29(10):18501876. doi: $10.1177 / 0886260513511701$.

Noncommercial - You may not use this work for commercial purposes. 